\title{
GMR
}

\section{Genotypic and allelic frequencies of gene polymorphisms associated with meat tenderness in Nellore beef cattle}

\author{
M.E. Carvalho ${ }^{1}$, J.P. Eler ${ }^{1}$, M.N. Bonin ${ }^{2}$, F.M. Rezende ${ }^{3}$, F.H. Biase ${ }^{4}$, \\ F.V. Meirelles ${ }^{1}$, L.C.A. Regitano ${ }^{5}$, L.L. Coutinho ${ }^{6}$, J.C.C. Balieiro ${ }^{7}$ and \\ J.B.S. Ferraz ${ }^{1}$ \\ ${ }^{1}$ Departamento Medicina Veterinária, \\ Faculdade de Zootecnia e Engenharia de Alimentos, \\ Universidade de São Paulo, Pirassununga, SP, Brasil \\ ${ }^{2}$ Embrapa Gado de Corte, Campo Grande, MS, Brasil \\ ${ }^{3}$ Instituto de Genética e Bioquímica, \\ Universidade Federal de Uberlândia, Patos de Minas, MG, Brasil \\ ${ }^{4}$ Department of Animal Sciences, Auburn University, Auburn, AL, USA \\ ${ }^{5}$ Embrapa Sudeste, São Carlos, SP, Brasil \\ ${ }^{6}$ Departamento de Ciência Animal, \\ Escola Superior de Agricultura "Luiz de Queiroz", \\ Universidade de São Paulo, Piracicaba, SP, Brasil \\ ${ }^{7}$ Departamento de Nutrição e Produção Animal, \\ Faculdade de Medicina Veterinária e Zootecnia, \\ Universidade de São Paulo, Pirassununga, SP, Brasil \\ Corresponding author: M.E. Carvalho \\ E-mail: minosec@gmail.com
}

Genet. Mol. Res. 16 (1): gmr16018957

Received July 11, 2016

Accepted December 6, 2016

Published February 16, 2017

DOI http://dx.doi.org/10.4238/gmr16018957

Copyright $(2017$ The Authors. This is an open-access article distributed under the terms of the Creative Commons Attribution ShareAlike (CC BY-SA) 4.0 License.

ABSTRACT. The objectives of this study were to characterize the allelic and genotypic frequencies of polymorphisms in the $\mu$-calpain and calpastatin genes, and to assess their association with meat tenderness and animal growth in Nellore cattle. We evaluated 605

Genetics and Molecular Research 16 (1): gmr16018957 
Nellore animals at 24 months of age, on average, at slaughter. The polymorphisms were determined for the molecular markers CAPN316, CAPN530, CAPN4751, CAPN4753, and UOGACAST1. Analyses of meat tenderness at 7, 14, and 21 days of maturation were performed in samples of longissimus thoracis obtained between the 12th and 13th rib and sheared using a Warner Bratzler Shear Force. Significant effects were observed for meat tenderness at days 7, 14, and 21 of maturation for the marker CAPN4751, at day 21 for the marker CAPN4753, and at days 14 and 21 for the marker UOGCAST1. For genotypic combinations of markers, the results were significant for the combination CAPN4751/UOGCAST1 in the three maturation periods and CAPN4753/UOGCAST1 at days 14 and 21 of maturation.

Keywords: Bos indicus; Calpain; Calpastatin; Nellore cattle; Polymorphism; Tenderness

\section{INTRODUCTION}

Bos indicus is preferred in tropical regions of Brazil owing to its resistance to disease and high tolerance to heat. This culminates in a cattle livestock characterized by the predominance of $B$. indicus animals, mainly Nellore, and its crosses. However, restrictions have been attributed to this breed for meat production, because of lower meat tenderness (Crouse et al., 1989). The issue of lower meat texture from B. indicus than from Bos taurus has been previously reported in studies by Ramsey et al. (1963), Shackelford et al. (1991), and Gallinger et al. (1992).

According to Andersson (2001), selection between Bos indicus animals is interesting because the herd base presents high phenotypic variation, and knowledge of the genetic basis of variation in the phenotype can greatly contribute to animal selection. The results obtained by Hadlich et al. (2006) confirmed this concept. Those authors observed a desirable degree of meat tenderness in young Nellore animals after just 7 days of maturation. Using molecular markers, de Souza et al. (2016) observed allele and parent-of-origin-specific effects on the expression of candidate genes for meat tenderness in Nellore beef cattle.

Meat tenderness (shear force) is a critical trait, since it is directly related to consumer satisfaction. Among the quality traits of in natura meat, tenderness is the most desired by consumers (Koohmaraie et al., 2002). Thus, there is great interest in the selection of animals with genetic traits that favor the reduction of meat tenderness variation (Page et al., 2004).

Koohmaraie (1996) reported that the enzyme $\mu$-calpain degrades myofibrillar muscle proteins during the meat tendering process. The process of meat tendering occurs postmortem initially through the action of calpain, and thus $\mu$-calpain is responsible for extending myofibrillar proteolysis. The tendering process ceases as calpain enters autolysis (Dransfield et al., 1992; Dransfield, 1993). Geesink et al. (2006) stated that $\mu$-calpain is the main proteolytic enzyme responsible for post-mortem myofibrillar proteolysis and, along with other proteins, should be studied to better understand the meat tendering process.

Calpastatin, an inhibitor of calpain, is the main regulator of proteolytic activity postmortem (Koohmaraie, 1988). Helical sequences in calpastatin prevent calpain from binding to membranes (Mellgren et al., 1989). In live muscle, high calpastatin activity reduces protein degradation (Morgan et al., 1993).

Genetics and Molecular Research 16 (1): gmr16018957 
Smith et al. (2000) identified a neutral protease gene activated by calcium (CAPN), which encodes $\mu$-calpain on chromosome 29. Bishop et al. (1993) identified the calpastatin gene on chromosome 7. These genes, along with the physiological functions of the enzymes, represent candidates for the selection of higher animals with better meat quality.

White et al. (2005) highlighted that difficulty in obtaining phenotypic data on meat tenderness explains why the selection and genetic improvement of this trait has been little developed. Studies show that marker-assisted selection (MAS) has the potential to improve characteristics historically reported as difficult to measure (White et al., 2005).

Based on the relationship between calpain and calpastatin, Casas et al. (2006) demonstrated the interaction of possible genotypes between genetic markers in the CAPN and calpastatin (CAST) genes, which significantly influenced the meat tenderness composite in B. taurus and B. indicus. The present study aimed to characterize the genotypic and allelic frequencies of polymorphisms in the CAPN and CAST genes and to associate these polymorphisms with weight gain and meat tenderness traits in Nellore cattle.

\section{MATERIAL AND METHODS}

\section{Animals evaluated and DNA extraction from blood samples}

The animals used in these experiments were obtained from farms belonging to Agropecuaria CFM Ltd. The herd is located in the western region of São Paulo State in Brazil. The dataset on growth development traits was obtained from Nucleus for Research Support in Animal Breeding Biotechnology and Transgeny (NAP-GMABT) of the Veterinary Medicine Department of the Faculty of Animal Science and Food Engineering of the University of São Paulo (FZEA/USP), in the city of Pirassununga, São Paulo State, Brazil.

DNA was extracted from 605 progenies (males) from blood samples collected with EDTA (Ethylenediamine tetraacetic acid) and blood-impregnated FTA ${ }^{\circledR}$ (Flinders Technology Associates) cards, by extracting and precipitating in $\mathrm{NaCl}$, following the protocol described by Olerup and Zetterquist (1992).

The progeny distribution per bull considered a minimum of three, and a maximum of 51 individuals per bull, representing 73 bulls in the population evaluated.

\section{Meat sampling for tenderness analysis}

Meat samples were collected at a commercial slaughterhouse of the Marfrig Group, following all recommended protocols for commercial slaughter under Brazilian legislation. As they reached a target weight, the animals were sent to slaughter. Three steaks, approximately $2.5 \mathrm{~cm}$ thick from the longissimus thoracis were collected from each of 605 animals, between the 12th and 13th rib toward the tail. The steaks were individually identified and vacuumpacked (Selovac M160) in highly flexible Polyfilm ${ }^{\circledR}$.

\section{Meat tenderness analysis (Shear force)}

The samples underwent a maturation process at $2^{\circ} \mathrm{C}$ for 7,14 , and 21 days postmortem, and were then evaluated for tenderness according to procedures recommended by AMSA (1995). From each sample, eight cylindrical subsamples $1.25 \mathrm{~cm}$ in diameter were

Genetics and Molecular Research 16 (1): gmr16018957 
collected with the aid of a metallic punch adapted to an electric drill, as proposed by Kastner and Henrickson (1969). Shear force was measured in a mechanical Warner Bratzler Shear Force with a cutting speed of $20 \mathrm{~cm} / \mathrm{min}$ and a $20-\mathrm{kg}$ capacity. The shear force of each sample is represented by the arithmetic mean of the shear force obtained from eight subsamples.

\section{Amplification and identification of polymorphisms}

Overall, 605 genotypes for five markers of the five SNP polymorphisms were characterized and confirmed by real-time PCR, using an ABI Prism ${ }^{\circledR} 7500$ sequence detection system (Applied Biosystems).

Allele frequencies and genotypes were determined using the $\operatorname{TaqMan}^{\mathrm{TM}}$ detection system, in which the primer and probe emit different fluorescence signals for each allele of the polymorphism, and are paired in the target DNA region, allowing the identification of different alleles by reading the fluorescence of each sample. When only one fluorescent signal is detected, the sample is homozygous for one allele, and when two different fluorescent signals are detected, the sample is heterozygous, considering the two possible alleles.

Probes were synthesized to pair selectively in the DNA template where the polymorphism of interest is located. Polymorphisms described in other populations, and which have their sequences deposited in GenBank, along with their respective primers, were used as the probe targets. The rate of heterozygous and homozygous individuals for one of their genotypes was estimated by the fluorescent signals from the probes.

For the PCR, we used approximately $15 \mathrm{ng}$ DNA for a reaction volume of $10 \mu \mathrm{L}$, containing $0.25 \mu \mathrm{L}$ Assay $\mathrm{Mix}^{\circledR}$ (Applied Biosystems), and 5.0 $\mu \mathrm{L}$ Taqman $^{\circledR}$ Master Mix Universal PCR (Applied Biosystems), under reaction conditions of $10 \mathrm{~min}$ at $95^{\circ} \mathrm{C}$, and 45 cycles of $15 \mathrm{~s}$ at $92^{\circ} \mathrm{C}$, and $1 \mathrm{~min}$ at $60^{\circ} \mathrm{C}$.

\section{Description of the genes investigated}

The markers used are described in Table 1, and were previously selected based on the reports of Casas et al. (2005), White et al. (2005), and Schenkel et al. (2006). The primers and probes that were used to amplify and discriminate alleles, respectively, are shown in Table 2.

Table 1. Description of the markers investigated, their respective chromosomes, introns and exons, nucleotide substitution, positions, GenBank accession No., and references.

\begin{tabular}{l|c|c|c|c|c|l}
\hline Markers & Chromosomes & Exons / Introns & Nucleotide substitution & Nucleotide position & GenBank accession No. & References \\
\hline CAPN 316 & 29 & Exon 9 & G/C & 5709 & AF252504 & Casas et al. (2005) \\
\hline CAPN 530 & 29 & Exon 14 & A/G & 4558 & AF248054 & Casas et al. (2005) \\
\hline CAPN 4751 & 29 & Intron 18 & C/T & 6545 & AF248054 & White et al. (2005) \\
\hline CAPN 4753 & 29 & Intron 21 & A/C & 8676 & AF248054 & Casas et al. (2005) \\
\hline UOGCAST1 & 07 & Intron 5 & C/G & 282 & AY008267 & Schenkel et al. (2006) \\
\hline
\end{tabular}

\section{Characterization of phenotypic information and genetic structure of the population}

Phenotypic information for the tenderness of matured meat evaluated at days 7 , 14 , and 21 , as well as the traits of weight at weaning, weaning-to-yearling weight gain, and yearling weight were subjected to verification of assumptions of data analysis (including normality and homogeneity of variance). These statistical analyses were performed with the

Genetics and Molecular Research 16 (1): gmr16018957 
aid of the Statistical Analysis System, version 9.1.3 (SAS, 2003) using PROC MEANS and UNIVARIATE procedures.

\begin{tabular}{|c|c|c|}
\hline Marker & Sequence & Probes \\
\hline CAPN316 & $\begin{array}{l}\text { F: GCAGTGCCGTTTTCCTACAG } \\
\text { R: AGCTGCTCCCGCATGTAAG }\end{array}$ & $\begin{array}{l}\text { CCACGGCGTTCCA } \\
\text { CCACGCCGTTCCA }\end{array}$ \\
\hline $\begin{array}{l}\text { CAPN530 } \\
\end{array}$ & $\begin{array}{l}\text { F: TTGACTGGCCCCTCTCTCT } \\
\text { R: GGCAGGGCACGTACCT }\end{array}$ & $\begin{array}{l}\text { ATGACCAGGTCCAGGC } \\
\text { ATGACCAGATCCAGGC }\end{array}$ \\
\hline CAPN4751 & $\begin{array}{l}\text { F: TGGCATCCTCCCCTTGACT } \\
\text { R: CCCCCGTCACTTGACACA }\end{array}$ & $\begin{array}{l}\text { CTGCGCCTCGGTTT } \\
\text { CTGCGCCTCAGTTT }\end{array}$ \\
\hline CAPN4753 & $\begin{array}{l}\text { F: GGGTCCCTCTCCCTCCTG } \\
\text { R: CGCCTCCCAGCTCCAT }\end{array}$ & $\begin{array}{l}\text { TCCTCCCTCTGTCAAGG } \\
\text { TCCTCCCTCTTTCAAGG }\end{array}$ \\
\hline UOGCAST1 & $\begin{array}{l}\text { F: GGAAGGAAGGAATTGCATTGTTTCA } \\
\text { R: CACTTGTGTTTTATGTAGTCAATTGTGAGAA }\end{array}$ & $\begin{array}{l}\text { CTTTGGGTAGAAAATT } \\
\text { TTGGGTACAAAATT }\end{array}$ \\
\hline
\end{tabular}

Allelic and genotypic frequencies based on the results generated by real-time PCR were estimated for each locus with simple allele and genotype counts, respectively, as described by Falconer and Mackay (2001).

\section{Effect of SNP markers on meat tenderness}

To assess the effects of genotypes on traits related to meat tenderness and weight gain, we used the information obtained from shear force, as well as animal performance, as dependent variables.

The effects of genotypes found for different markers, considering the different days of maturation, and weight gain traits, were evaluated using the model described by Casas et al. (2005), White et al. (2005), and Casas et al. (2006), as follows:

$$
Y i_{j k l}=\mu+C_{i}+S_{j}+M_{k}+\beta_{1}\left(I_{i j k l}-I\right)+e_{i j k l} \quad \text { (Equation 1) }
$$

where: $Y_{i j k l}=$ the observed phenotypic value for tenderness; $\mu=$ the inherent constant of all observations; $C_{i}=$ the fixed effect of the contemporary group; $S_{j}=$ the random effect of sire, with mean 0 and variance $s_{s}^{2} ; M_{k}=$ the fixed effect of genotype for marker (CAPN316, CAPN530, CAPN4751, CAPN4753, and UOGCAST1); $b_{1}=$ is the linear regression coefficient of traits $Y_{i j k l}$ in relation to deviation of the animal age at slaughter, included in the model as a covariate; $I_{i j k l}=$ animal age at measurement or slaughter; $\overline{\mathrm{I}}=$ the mean age of animals evaluated at measurement or slaughter; $e_{i j k l}=$ the random residual effect associated with characteristic $Y_{i j k l}$, with mean 0 and variance $\mathrm{s}^{2}$.

The composition of contemporary groups for variables related to meat tenderness at days 7,14 , and 21 , and variables for weight gain, were characterized by animals born within the same herd, in the same year, same season, of the same sex, of the same management group until weaning, and belonging to the same weaning-to-yearling management group. For weight at weaning, we included the effect of age class of the mother at calving to the model above.

To test other effects of genotypic combinations, considering two loci simultaneously for meat tenderness, we adopted the statistical model previously cited, changing the effect $M_{k}$ for $G_{k}$, wherein $G_{k}$ represents the kth genotypic combination for both loci. 


\section{RESULTS AND DISCUSSION}

\section{Characterization of phenotypic information evaluated}

Phenotypic information following critical analysis and file consistency, for outliers, missing data, normality and homogeneity of variance, are show in Table 3 . Shear force at day 7 (SF7D), 14 (SF14D), and 21 (SF21D), and the traits weight gain, weaning weight (WW), yearling weight (W18), weaning-to-yearling weight gain (WG345), and age at slaughter of animals (ID SLAUG) are shown. The animals were young, and small variations in age among animals are important when obtaining and comparing the phenotypic measures of growth and shear force.

Table 3. Numbers of observations (N), mean (MEAN), standard deviations (SD), coefficients of variation $(\mathrm{CV})$, minimum (MIN), and maximum (MAX) for the traits.

\begin{tabular}{l|c|c|c|c|c|c}
\hline Traits & $\mathrm{N}$ & Mean & SD & CV (\%) & MIN & MAX \\
\hline SF7D* & 590 & 58.25 & 14.31 & 24.56 & 17.84 & 97.96 \\
\hline SF14D* & 590 & 48.54 & 12.84 & 26.39 & 12.94 & 91.59 \\
\hline SF21D* & 594 & 42.95 & 10.98 & 25.64 & 15.78 & 83.65 \\
\hline WW** & 604 & 196.82 & 24.66 & 12.53 & 89.00 & 272.00 \\
\hline W18M** & 588 & 321.25 & 32.63 & 10.16 & 231.00 & 451.00 \\
\hline WG345** & 588 & 125.37 & 28.10 & 22.42 & 60.00 & 213.00 \\
\hline ID SLAUG *** & 580 & 24.25 & 1.66 & 6.86 & 21.00 & 34.00 \\
\hline
\end{tabular}

*Shear force in Newton; **weight in kilograms; ***age in months.

\section{Genetic structure of the population for the markers evaluated}

The distribution of the genic and genotypic frequency within the population for markers CAPN316 and CAPN530 was irregular and low for one of the alleles, which prevented consistent data analysis for these two markers. For CAPN316, the absence of genotype C/C and a low allelic frequency, which is favorable for meat tenderness, hindered the association analysis between variables of weight development and meat tenderness. Corva et al. (2007) studied crossbred Angus, Hereford, and Limousin animals, and observed the frequency of the $\mathrm{C}$ allele to range from 0.27 to 0.46 , which is much higher than that found in the present study. Li et al. (2013) assessed Angus, Charolais, Hereford, Limousin, and Simmental animals and observed frequencies for the $\mathrm{C}$ allele of $0.36,0.14,0.03,0.16$, and 0.17 , respectively. Similar to results observed in Nellore animals for the C/C genotype in this study, Li et al. (2013) did not observe the homozygous genotype $\mathrm{C} / \mathrm{C}$ in Hereford, Limousin, or Simmental. The remaining markers showed genotype frequencies that were sufficiently distributed to enable analyses of individual and paired markers to take place when convenient.

Genotypic and allelic frequencies associated with the five polymorphisms evaluated are shown in Tables 4 and 5.

In the animals evaluated, the genic frequency observed for the CAPN316 marker showed that $\mathrm{G}$ alleles are practically fixed in this population. This is consistent with the findings of Casas et al. (2005), who reported frequencies associated with $\mathrm{C}$ allele of 0.0012 in 470 animals of the Brahman breed. These low frequencies of the $\mathrm{C}$ allele suggest that polymorphisms may have occurred only in animals of $B$. taurus origin following the divergence of the subspecies B. indicus and B. taurus. Another hypothesis is that the rare $\mathrm{C}$ allele observed in this Nellore population may have been generated by breeding during the formation phase of

Genetics and Molecular Research 16 (1): gmr16018957 
Table 4. Genotypic frequencies observed for the markers evaluated in Nellore cattle.

\begin{tabular}{|c|c|c|c|}
\hline Markers & Genotype & Frequencies & Cumulative frequencies \\
\hline & $\mathrm{C} / \mathrm{C}$ & 0 & 0 \\
\hline \multirow[t]{2}{*}{ CAPN316 } & $\mathrm{C} / \mathrm{G}$ & 10 & 10 \\
\hline & $\mathrm{G} / \mathrm{G}$ & 593 & 603 \\
\hline \multicolumn{4}{|c|}{ Number of samples that did not amplify $=02$} \\
\hline & $\mathrm{A} / \mathrm{A}$ & 2 & 2 \\
\hline \multirow[t]{2}{*}{ CAPN530 } & $\mathrm{A} / \mathrm{G}$ & 85 & 87 \\
\hline & $\mathrm{G} / \mathrm{G}$ & 515 & 602 \\
\hline \multicolumn{4}{|c|}{ Number of samples that did not amplify $=03$} \\
\hline & $\mathrm{C} / \mathrm{C}$ & 19 & 19 \\
\hline \multirow[t]{2}{*}{ CAPN4751 } & $\mathrm{C} / \mathrm{T}$ & 175 & 194 \\
\hline & $T / T$ & 408 & 602 \\
\hline \multicolumn{4}{|c|}{ Number of samples that did not amplify $=03$} \\
\hline & $\mathrm{A} / \mathrm{A}$ & 106 & 106 \\
\hline \multirow[t]{2}{*}{ CAPN4753 } & $\mathrm{A} / \mathrm{C}$ & 169 & 275 \\
\hline & $\mathrm{C} / \mathrm{C}$ & 283 & 558 \\
\hline \multicolumn{4}{|c|}{ Number of samples that did not amplify $=47$} \\
\hline & $\mathrm{C} / \mathrm{C}$ & 232 & 232 \\
\hline \multirow[t]{2}{*}{ UOGCAST1 } & $\mathrm{C} / \mathrm{G}$ & 280 & 512 \\
\hline & $\mathrm{G} / \mathrm{G}$ & 87 & 599 \\
\hline
\end{tabular}

Table 5. Allelic frequencies estimated for the markers evaluated in Nellore cattle.

\begin{tabular}{l|c|c}
\hline \multirow{2}{*}{ Markers } & \multicolumn{2}{|c}{ Allelic frequencies } \\
\cline { 2 - 3 } & $(\mathrm{p})$ & $(\mathrm{q})$ \\
\hline CAPN316 & $\mathrm{f}(\mathrm{C})=0.0083$ & $\mathrm{f}(\mathrm{G})=0.9917$ \\
\hline CAPN530 & $\mathrm{f}(\mathrm{A})=0.0739$ & $\mathrm{f}(\mathrm{G})=0.9261$ \\
\hline CAPN4751 & $\mathrm{f}(\mathrm{C})=0.1769$ & $\mathrm{f}(\mathrm{T})=0.8231$ \\
\hline CAPN4753 & $\mathrm{f}(\mathrm{A})=0.3414$ & $\mathrm{f}(\mathrm{C})=0.6586$ \\
\hline UOGCAST1 & $\mathrm{f}(\mathrm{C})=0.6210$ & $\mathrm{f}(\mathrm{G})=0.3790$ \\
\hline
\end{tabular}

the current herd. For Hanwoo taurine, Lee et al. (2014) observed a lower frequency of the G allele (0.33) in a population of 291 animals, and the $\mathrm{C}$ allele, which is favorable for tenderness, was observed at the highest frequency (0.67). Furthermore, in B. taurus, Johnston and Graser (2010) reported a frequency of 0.57 for the G allele in Angus animals. For the CAPN530 marker, the frequency of the A allele, which is considered favorable, was very low in relation to $\mathrm{G}$ allele (Table 5), which was not considered to be informative. This is consistent with the findings of White et al. (2005) who analyzed Brahman animals using the same marker.

Those authors also reported a frequency of 0.13 for the favorable A allele in animals of Cycle 8 of the Germplasm Assessment Project of the Meat Animal Research Center in Clay Center/Nebraska. However, in animals of B. taurus origin, Allais et al. (2011) reported a different distribution for the alleles of this marker. Those authors found that the A allele was present at a frequency of 0.24 in Charolais cattle and 0.36 in Limousin cattle.

The low frequency of favorable alleles for both markers CAPN316 and CAPN530 obtained in the present study shows these are ineffective in Nellore populations. Other authors have reported frequencies similar to those found in the present study. Therefore, use of the markers CAPN316 and CAPN530 in animals of B. indicus origin is not recommended for the identification of genetically superior animals for the traits considered.

Allelic frequencies observed for the marker CAPN4751 showed that the favorable C allele was present at lower frequency than the T allele. Curi et al. (2009) evaluated Nellore animals and observed the $\mathrm{C}$ allele at a frequency of 0.10 ; however, sampling of 114 animals 
revealed no homozygosity for the $\mathrm{C}$ allele. With similar results in Brahman cattle, White et al. (2005) reported frequencies of 0.096 for the $\mathrm{C}$ allele, and both studies reported the frequency of this allele to be lower than that observed in the present study. Those authors also reported that the frequency of the $\mathrm{C}$ allele was 0.576 for crossed animals of Cycle 7 and 0.640 for crossed animals of Cycle 8 from the Germplasm Assessment Project of the Meat Animal Research Center in Clay Center/Nebraska. Importantly, the animals from Cycles 7 and 8 of this project are composites, products of crossings between animals of taurine origin. For the marker CAPN4753, the frequency of the A allele, which is considered favorable, was lower when compared to that of the $\mathrm{C}$ allele. Casas et al. (2005) reported a higher frequency of the A allele ( $\mathrm{f}(\mathrm{A})=0.675)$ in Brahman animals raised in Florida, USA. However, White et al. (2005) observed a frequency of $6.1 \%$ for the same allele in composite populations.

Genic frequencies observed for the marker UOGCAST1 showed that the frequency of the favorable $\mathrm{C}$ allele is higher than that of the $\mathrm{G}$ allele. Schenkel et al. (2006) reported a C allele frequency of 0.629 for 628 animals from crosses between taurine breeds Angus, Limousin, Charolais, and Simmental. In the present study, the population studied was B. indicus; however, the genic frequency was very similar to that observed for taurine animals. These findings suggest that the UOGCAST1 marker has greater applicability and could be used in animals of both origins, with the aim of identifying animals with traits of greater meat tenderness.

\section{Effects of evaluated SNP markers}

No significant effects $(\mathrm{P}>0.05)$ of the SNP markers were observed on the weight gain traits evaluated. However, significant results were observed $(\mathrm{P}<0.05)$ for tenderness-related traits in different maturation periods.

Mean least-squares and standard error estimates (expressed in Newton) associated with the genotypic effects of the markers assessed, as well as the likelihood values observed in the $\mathrm{F}$ Tests for individual variance analyses for tenderness-related traits at days 7, 14 and 21 of maturation (SF7D, SF14D, and SF21D, respectively), are shown in Table 6.

Table 6. Estimates of means and standard errors (SE), as well as probability values observed in the $\mathrm{F}$ tests associated with the effects of the genotypes of markers evaluated for shear force traits at 7, 14, and 21 days of maturation.

\begin{tabular}{|c|c|c|c|c|}
\hline \multirow[t]{2}{*}{ Markers } & \multicolumn{4}{|c|}{ Genotypes } \\
\hline & Mean \pm SE & Mean \pm SE & Mean \pm SE & \\
\hline CAPN530 & $\mathrm{A} / \mathrm{A}$ & $\mathrm{A} / \mathrm{G}$ & $\mathrm{G} / \mathrm{G}$ & $\operatorname{Pr}>F^{a}$ \\
\hline SF7D $^{\mathrm{b}}$ & $71.58 \pm 10.10$ & $60.60 \pm 1.96$ & $60.50 \pm 1.27$ & 0.5448 \\
\hline SF14D & $49.42 \pm 9.12$ & $50.99 \pm 1.76$ & $49.91 \pm 1.17$ & 0.7850 \\
\hline SF21D ${ }^{d}$ & $40.50 \pm 7.94$ & $45.89 \pm 1.47$ & $44.32 \pm 0.98$ & 0.4371 \\
\hline CAPN4751 & $\mathrm{C} / \mathrm{C}$ & $\mathrm{C} / \mathrm{T}$ & $\mathrm{T} / \mathrm{T}$ & $\operatorname{Pr}>F$ \\
\hline SF7D $^{\mathrm{b}}$ & $60.50 \pm 3.43$ & $58.05 \pm 1.56$ & $61.68 \pm 1.37$ & 0.0293 \\
\hline SF14D & $47.26 \pm 3.13$ & $48.34 \pm 1.37$ & $51.09 \pm 1.17$ & 0.0486 \\
\hline SF21D ${ }^{d}$ & $41.08 \pm 2.64$ & $41.87 \pm 1.17$ & $46.28 \pm 1.07$ & $<0.0001$ \\
\hline CAPN4753 & $\mathrm{A} / \mathrm{A}$ & $\mathrm{A} / \mathrm{C}$ & $\mathrm{C} / \mathrm{C}$ & $\operatorname{Pr}>F$ \\
\hline SF7D $^{b}$ & $62.56 \pm 1.76$ & $58.74 \pm 1.56$ & $59.42 \pm 1.37$ & 0.0907 \\
\hline SF14 & $52.17 \pm 1.56$ & $49.32 \pm 1.37$ & $49.03 \pm 1.27$ & 0.1116 \\
\hline SF21D & $47.56 \pm 1.37$ & $43+93 \pm 1.17$ & $44.12 \pm 1.07$ & 0.0188 \\
\hline UOGCAST1 & $\mathrm{C} / \mathrm{C}$ & $\mathrm{C} / \mathrm{G}$ & $\mathrm{G} / \mathrm{G}$ & $\operatorname{Pr}>F$ \\
\hline SF7D $^{b}$ & $59.03 \pm 1.47$ & $61.68 \pm 1.47$ & $60.80 \pm 1.96$ & 0.1158 \\
\hline SF14 ${ }^{\mathrm{c}}$ & $48.24 \pm 1.27$ & $50.99 \pm 1.27$ & $53.25 \pm 1.76$ & 0.0045 \\
\hline SF21D ${ }^{d}$ & $42.65 \pm 1.07$ & $46.28 \pm 1.07$ & $46.58 \pm 1.56$ & 0.0006 \\
\hline
\end{tabular}

${ }^{a} \mathrm{Pr}>\mathrm{F}=$ Probability values observed for the F-test analyzes of variance to identify variation in markers; ${ }^{\mathrm{S}} \mathrm{SF}$ 7D $=$ shear force of steaks aged 7 days in Newton; ${ }^{\mathrm{c} S F} 14 \mathrm{D}=$ shear force of steaks aged 14 days in Newton; ${ }^{\mathrm{d}} \mathrm{SF} 21 \mathrm{D}=$ shear force of steaks aged 21 days in Newton.

Genetics and Molecular Research 16 (1): gmr16018957 
Data in Table 6 indicate that, for the marker CAPN530, no significant results were observed for the genotypes in the variables SF7D, SF14D, and SF21D. Corva et al. (2007) did not observe genotype A/A; however, those authors obtained significant effects for tenderness of non-matured meat between genotypes $\mathrm{A} / \mathrm{G}$ and $\mathrm{G} / \mathrm{G}$ in animals of $B$. Taurus origin. The results obtained for that marker in the present study are consistent with those reported by White et al. (2005), who observed no association between this marker and shear force in the population of crossed animals of Cycle 8 from the Germplasm Assessment Project of MARC, in Clay Center/ Nebraska. However, significance was detected for the other markers, as listed below.

For the marker CAPN4751, significant effects were observed on SF7D and SF14D (P $<0.05)$, and on SF21D ( $<0.01)$. These results corroborate the findings of White et al. (2005), who also observed significant effects on the marker in B. indicus, B. taurus, and crossed animals. Those authors estimated differences in tenderness of $-3.92,-2.64$, and $-4.31 \mathrm{~N}$, respectively, in this population, between animals with the genotypes $\mathrm{T} / \mathrm{T}$ (unfavorable) in relation to $\mathrm{C} / \mathrm{C}$ (favorable), for meat matured for 14 days. Curi et al. (2009) evaluated animals of different breeds (Nellore, Angus x Nellore, Rubia Galega x Nellore, Canchim, Brangus three-way cross, and Braunvieh three-way cross) and observed differences in meat tenderness between animals with CT and TT genotypes; however, animals with the CC genotype were not used in the population analyzed by those authors. Additionally, Pinto et al. (2011) observed that additive effects of alleles for the $\mathrm{CC}$ genotype of this marker may be associated with a less intense red color. Therefore, important information on this genotype should also be considered.

The significant results obtained for populations of different origins suggest that this marker may have general applicability for cattle, and can be considered an interesting alternative for the identification of animals with greater meat tenderness.

For the marker CAPN4753, significant effects were observed only for the SF21D variable $(\mathrm{P}<0.01)$, and the traits SF7D and SF14D were considered non-significant $(\mathrm{P}>0.05)$. The results for the marker CAPN4753 in this study differ from those reported by Casas et al. (2005), who found significant differences $(\mathrm{P}>0.05)$ in meat tenderness by the Warner Bratzler Shear Force for meats at days 7, 14, and 21 of maturation in Brahman animals. However, White et al. (2005) observed segregation of the A allele with a frequency of $6.1 \%$ and a significant association with shear force $(\mathrm{P}=0.041)$ in composite populations.

A comparison of the results found in the present study with those reported previously highlights the segregation of alleles with favorable effects in animals of $B$. indicus origin, which are only available to date in the literature for composite animals of taurine origin.

For the marker UOGCAST1, significant results were also confirmed for SF14D and SF21D $(P<0.01)$, while for SF7D, no significant results were detected $(\mathrm{P}>0.05)$. These results for tenderness-related traits partially corroborate those obtained by Schenkel et al. (2006), who reported significant differences $(\mathrm{P}<0.05)$ for tenderness assessed in the Warner Bratzler Shear Force for meats after 21 days of maturation. In the present study, the results were clearer because significant differences $(\mathrm{P}<0.01)$ were observed for this marker in meats at days 14 and 21 of maturation. Chung and Davis (2012) also evaluated the calpastatin gene in Hanwoo cattle, although another nucleotide exchange was used (C641T, AF281256 sequence), and a polymorphism association with shear force and calpastatin activity was observed.

Figure S1 illustrates the average values for meat tenderness in individuals of each genotype within three maturation periods, for individual analyses of the markers CAPN530, CAPN4751, CAPN4753, and UOGCAST1. Only data for the CAPN530 marker showed no significant effects, possibly due to the high standard errors observed for A/A genotypes. This

Genetics and Molecular Research 16 (1): gmr16018957 
may be attributed to irregularity in the distribution of genotypes. Genotype A/A showed a reduced frequency in the population, as observed in Table 4.

In terms of meat maturation, the data were regular. Reduced tenderness values for the three maturation periods occurred for all genotypes, regardless of the marker assessed. Figure S1 shows there were no discrepancies in the results for meat maturation.

\section{Effect of genotypic combination of SNP markers on meat tenderness}

The effects of genotype combinations on the meat tenderness trait at days 7, 14, and 21 of maturation were evaluated for the markers CAPN4751 and UOGCAST1, as well as for CAPN4753 and UOGCAST1, which occurred in all genotypes when arranged in pairs.

Table 7 shows the distribution of animals, estimates for contrasts, standard errors associated with the effects of genotypes on markers CAPN4751 and UOGCAST, and likelihood values observed in the F Tests of analyses of joint variances. These results were obtained from the simultaneous review of markers for tenderness traits in meat matured at days 7, 14, and 21 (SF7D, SF14D, and SF21D, respectively).

Table 7. Data of animals (N), estimates for the contrasts (EST), and standard error (SE) associated with the effects of genotypes of the markers CAPN4751 and UOGCAST1, evaluated simultaneously for shear force matured meat 7,14 , and 21 days.

\begin{tabular}{|c|c|c|c|c|c|c|c|}
\hline \multirow[t]{3}{*}{ Trait $^{\mathrm{a}}$} & \multirow{3}{*}{$\begin{array}{c}\text { Marker } \\
\text { CAPN4751 }\end{array}$} & \multicolumn{6}{|c|}{ Marker UOGCAST1 } \\
\hline & & \multicolumn{2}{|c|}{$\mathrm{CC}$} & \multicolumn{2}{|c|}{ CG } & \multicolumn{2}{|c|}{ GG } \\
\hline & & $\mathrm{EST} \pm \mathrm{SE}$ & $\mathrm{N}$ & $\mathrm{EST} \pm \mathrm{SE}$ & $\mathrm{N}$ & $\mathrm{EST} \pm \mathrm{SE}$ & $\mathrm{N}$ \\
\hline \multirow[t]{3}{*}{ SF7D $^{b}$} & $\mathrm{CC}$ & $-6.98 \pm 8.23$ & 3 & $-5.31 \pm 4.31$ & 11 & $-3.63 \pm 6.37$ & 5 \\
\hline & $\mathrm{CT}$ & $-5.15 \pm 1.76$ & 70 & $-3.49 \pm 1.66$ & 75 & $-1.82 \pm 2.94$ & 24 \\
\hline & TT & $-3.34 \pm 1.17$ & 153 & $-1.66 \pm 1.07$ & 185 & $0.00 \pm 2.15$ & 46 \\
\hline \multicolumn{8}{|c|}{$\operatorname{Pr}=0.0163$} \\
\hline \multirow[t]{3}{*}{ SF14D } & $\mathrm{CC}$ & $-9.97 \pm 6.96$ & 3 & $-7.28 \pm 3.62$ & 11 & $-4.59 \pm 5.39$ & 5 \\
\hline & CT & $-7.67 \pm 1.47$ & 70 & $-4.99 \pm 1.47$ & 75 & $-2.29 \pm 2.45$ & 24 \\
\hline & TT & $-5.37 \pm 0.98$ & 153 & $-2.68 \pm 0.88$ & 185 & $0.00 \pm 1.76$ & 46 \\
\hline \multicolumn{8}{|c|}{$\operatorname{Pr}<0.0001$} \\
\hline \multirow[t]{3}{*}{ SF21D } & $\mathrm{CC}$ & $-11.56 \pm 6.17$ & 3 & $-8.98 \pm 3.23$ & 11 & $-6.39 \pm 4.80$ & 5 \\
\hline & CT & $-8.36 \pm 1.27$ & 70 & $-5.78 \pm 1.27$ & 75 & $-3.19 \pm 2.15$ & 24 \\
\hline & TT & $-5.16 \pm 0.88$ & 153 & $-2.58 \pm 0.78$ & 185 & $0.00 \pm 1.56$ & 46 \\
\hline $\operatorname{Pr}<0.00$ & & & & & & & \\
\hline
\end{tabular}

${ }^{a}$ Expressed in deviations for shear force obtained by Warner Bratzler Shear Force (WBSF), in Newton; ${ }^{\text {bSF7D }}=$ shear force of steaks aged 7 days; 'SF14D = shear force of steaks aged 14 days; ${ }^{\text {d SF2 } 1 D ~=~ s h e a r ~ f o r c e ~ o f ~ s t e a k s ~}$ aged 21 days.

The data presented in Table 7 show that the $\mathrm{C}$ allele is favorable for the markers $\mu$-calpain and calpastatin, resulting in lower values for shear force (deviations expressed in Newton) indicating greater meat tenderness.

The nine possible genotypic combinations found in the individuals assessed revealed the existence of significant effects of genotypic combinations on the characteristics SF7D, SF14D, and SF21D in the three maturation periods. As the genotypic combinations include the favorable alleles, in this case $\mathrm{C}$ alleles, we observed reduced estimates for shear force, in Newton, showing increased tenderness at different days of meat maturation.

White et al. (2005) and Schenkel et al. (2006) reported significant effects on meat tenderness when evaluating the markers in the single-marker analysis. The significant 
association of meat tenderness with genotypic combinations for two different polymorphisms in calpain was also reported by Page et al. (2004) in a study using animals of taurine origin. Table 7 shows that meat tenderness was reduced, on average, $6.9 \mathrm{~N}$ for SF7D, $9.9 \mathrm{~N}$ for SF14D, and 11.5 N for SF21D, when four favorable alleles are present in comparison to genotypic combinations that do not have favorable alleles for both markers.

Pinto et al. (2010) investigated the same population and identified epistasis between the markers CAPN4751 and UOGCAST, considering the two markers simultaneously in a statistical model of cross-classification. In the present study, we used a multiple regression approach to evaluate the number of favorable alleles for both markers together. Thus, the traits of interest were assessed based on the regression of genotypic combinations expressed in terms of the number of favorable alleles found in the animal $(0,1,2,3$, or 4$)$. This approach assesses the possibility of alleles from different loci having distinct additive magnitudes of effects, which are added to assist the expression of the trait in question.

Analyses of genotypic combinations composed of other calpastatin markers have also been reported. In this type of analysis, even favorable alleles of different markers and different weights increased the average estimated values of meat tenderness. This increase in tenderness reinforces the recommendations for MAS as an effective tool to identify unused genotypes. However, depending on the population to be evaluated, difficulty may arise in the identification of genotypes with all favorable alleles for the desirable trait. In the present study, the population carried all possible genotypic combinations, which also allowed data analyses to be performed with greater consistency, given the existence of all genotype classes between the markers. White et al. (2005), for example, were unable to identify all genotypic combinations in simultaneous studies on the markers CAPN316 and CAPN4751.

Figure 1 shows the behavior of average estimates of shear force for all possible genotypic combinations at days 7 (SF7D), 14 (SF14D), and 21 (SF21D), for the markers CAPN4751 and UOGCAST1.

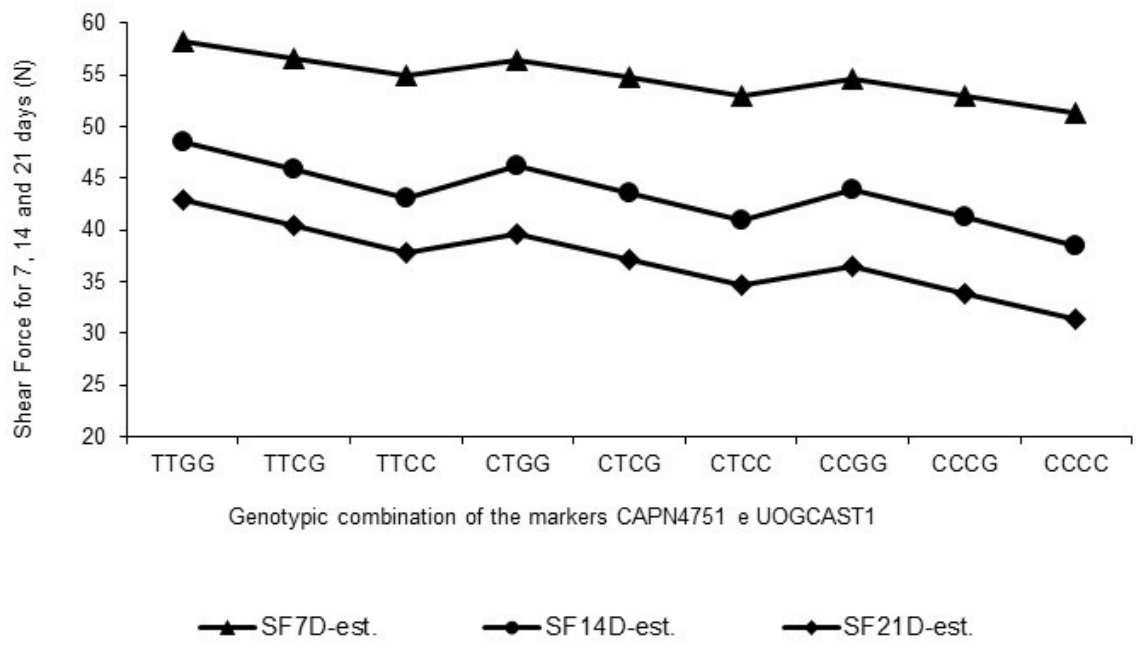

Figure 1. Estimates of shear force effects for genotypic combinations on markers CAPN4751 and UOGCAST1 for meat matured for 7,14 , and 21 days.

Genetics and Molecular Research 16 (1): gmr16018957 
We observed variation in the values for shear force for some combinations, leading to combinations that are more favorable. This can be explained by the difference in the allelic effects of each marker, which assume different estimates. If the favorable alleles of two markers had the same effect, a linear reduction in the values would be obtained until the minimum value for shear force for the combination $\mathrm{C} / \mathrm{C} / \mathrm{C} / \mathrm{C}$ was reached.

Table 8 shows the distribution of animals, estimates for contrasts, standard errors associated (in Newton) with the effects of genotypes, and the likelihood of values observed in the F Tests for variance in the markers CAPN4753 and UOGCAST1. These results were also obtained in simultaneous reviews of markers for tenderness traits of meat maturated for 7, 14, and 21 days (SF7D, SF14D, and SF21D, respectively).

\begin{tabular}{|c|c|c|c|c|c|c|c|}
\hline \multirow[t]{3}{*}{ Traits $^{\mathrm{a}}$} & \multirow{3}{*}{$\begin{array}{c}\text { Marker } \\
\text { CAPN4753 }\end{array}$} & \multicolumn{6}{|c|}{ Marker UOGCAST1 } \\
\hline & & \multicolumn{2}{|c|}{$\mathrm{CC}$} & \multicolumn{2}{|c|}{ CG } & \multicolumn{2}{|l|}{ GG } \\
\hline & & $\mathrm{EST} \pm \mathrm{SE}$ & $\mathrm{N}$ & $\mathrm{EST} \pm \mathrm{SE}$ & $\mathrm{N}$ & $\mathrm{EST} \pm \mathrm{SE}$ & $\mathrm{N}$ \\
\hline & $\mathrm{CC}$ & $-4.68 \pm 1.47$ & 102 & $-3.14 \pm 1.27$ & 139 & $-1.59 \pm 2.54$ & 32 \\
\hline \multirow[t]{2}{*}{$\mathrm{SF}_{\mathrm{S}} \mathrm{D}^{\mathrm{b}}$} & $\mathrm{AC}$ & $-3.88 \pm 1.96$ & 56 & $-2.34 \pm 1.66$ & 78 & $-0,80 \pm 2.94$ & 25 \\
\hline & AA & $-3.07 \pm 2.05$ & 49 & $-1.53 \pm 2.25$ & 40 & $0.00 \pm 4.11$ & 32 \\
\hline \multicolumn{8}{|c|}{$\operatorname{Pr}=0.0641$} \\
\hline & $\mathrm{CC}$ & $-7.50 \pm 1.27$ & 102 & $-4.91 \pm 1.07$ & 139 & $-2.32 \pm 2.15$ & 32 \\
\hline \multirow[t]{2}{*}{ SF14D } & $\mathrm{AC}$ & $-6.34 \pm 1.66$ & 56 & $-3.75 \pm 1.37$ & 78 & $-1.16 \pm 2.54$ & 25 \\
\hline & AA & $-5.17 \pm 1.76$ & 49 & $-2.58 \pm 1.96$ & 40 & $0.00 \pm 3.53$ & 32 \\
\hline \multicolumn{8}{|c|}{$\operatorname{Pr}=0.0005$} \\
\hline & $\mathrm{CC}$ & $-7.62 \pm 1.07$ & 102 & $-5.07 \pm 0.98$ & 139 & $-2.52 \pm 1.96$ & 32 \\
\hline \multirow[t]{2}{*}{$\mathrm{SF}_{11 \mathrm{D}^{\mathrm{d}}}$} & $\mathrm{AC}$ & $-6.37 \pm 1.47$ & 56 & $-3.81 \pm 1.27$ & 78 & $-1.25 \pm 2.15$ & 25 \\
\hline & AA & $-5.11 \pm 1.56$ & 49 & $-2.54 \pm 1.66$ & 40 & $0.00 \pm 3.13$ & 32 \\
\hline $\operatorname{Pr}<0.000$ & & & & & & & \\
\hline
\end{tabular}

${ }^{a}$ Expressed in deviations for shear force obtained by Warner Bratzler Shear Force (WBSF), in Newton; ${ }^{b}$ SF7D = shear force of steaks aged 7 days; 'SF14D = shear force of steaks aged 14 days; ${ }^{d}$ SF21D $=$ shear force of steaks aged 21 days.

In these analyses, the effects of the $\mathrm{C}$ alleles were also favorable and significant for traits of markers SF14D and SF21D of $\mu$-calpain and calpastatin.

Table 8 shows that genotypic combinations with the $\mathrm{C}$ allele, for combination with four favorable $\mathrm{C}$ alleles, showed increased meat tenderness at days 14 and 21 of maturation, on average, of approximately $7.5 \mathrm{~N}$ and $7.6 \mathrm{~N}$, respectively.

We highlight that simultaneous analyses involving the markers CAPN4753 and UOGCAST1 have not been reported in literature.

The graph in Figure 2 shows the average estimates of shear force for all possible genotypic combinations at days 7 (SF7D), 14 (SF14D), and 21 (SF21D), for the markers CAPN4753 and UOGCAST1.

In this second combination involving the marker CAPN4753, the reduction in shear force was smaller. This can be explained by the marker CAPN4753 exerting a smaller effect on shear force, when compared with the marker CAPN4751 (Table 8), where the markers were analyzed separately. In this case, the differences in the allelic effects at each locus evaluated also explained the variation in shear force values for genotype combinations, moving toward the most favorable combination of $\mathrm{C} / \mathrm{C} / \mathrm{C} / \mathrm{C}$.

Genetics and Molecular Research 16 (1): gmr16018957 


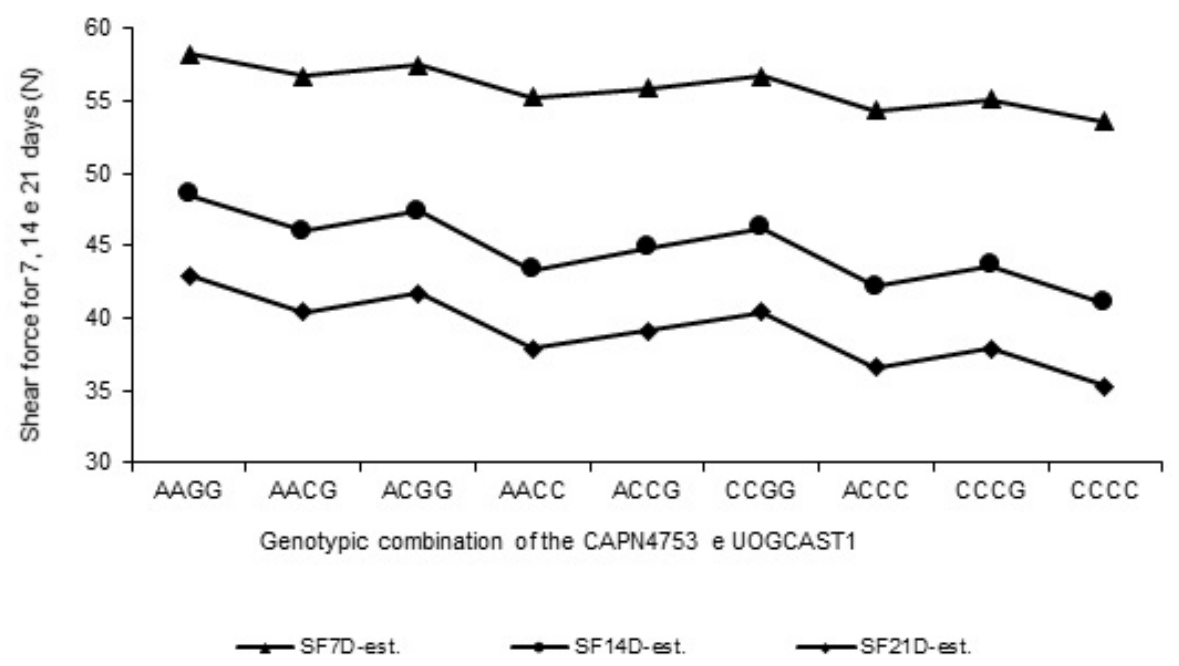

Figure 2. Estimates of shear force effects for genotypic combinations on markers CAPN4753 and UOGCAST1 in meat matured for 7,14 , and 21 days.

In conclusion, the marker CAPN316 was found to be practically fixed in the population evaluated, and the presence of the favorable $\mathrm{C}$ allele was observed at an extremely low frequency. The markers assessed did not generate significant results for traits of weight development. Differences in meat tenderness in relation to genotype combinations for polymorphisms of $\mu$-calpain and calpastatin indicate the viability of the markers CAPN4751, CAPN4753, and UOGCAST1 for use as molecular tools for the improvement of meat quality in Nellore cattle. Selecting meat quality based on these markers may not affect weight development, since this effect was not observed on the measurements of weight development.

\section{Conflicts of interests}

The authors declare no conflict of interest.

\section{ACKNOWLEDGMENTS}

We thank the São Paulo Research Foundation (FAPESP) and Scientific Research Foundation of Ribeirão Preto (FUNPEC-RP) for financial support.

\section{REFERENCES}

Allais S, Journaux L, Levéziel H, Payet-Duprat N, et al. (2011). Effects of polymorphisms in the calpastatin and $\mu$-calpain genes on meat tenderness in 3 French beef breeds. J. Anim. Sci. 89: 1-11. http://dx.doi.org/10.2527/jas.2010-3063 American Meat Science Association (AMSA) (1995). Research guidelines for cookery, sensory evaluation, and instrumental tenderness measurements of Meat. 1st edition. American Meat Science Association, Chicago.

Andersson L (2001). Genetic dissection of phenotypic diversity in farm animals. Nat. Rev. Genet. 2: 130-138. http:// dx.doi.org/10.1038/35052563

Bishop MD, Koohmaraie M, Killefer J and Kappes S (1993). Rapid communication: restriction fragment length 
polymorphisms in the bovine calpastatin gene. J. Anim. Sci. 71: 2277.

Casas E, White SN, Riley DG, Smith TP, et al. (2005). Assessment of single nucleotide polymorphisms in genes residing on chromosomes 14 and 29 for association with carcass composition traits in Bos indicus cattle. J. Anim. Sci. 83: 13-19. http://dx.doi.org/10.2527/2005.83113x

Casas E, White SN, Wheeler TL, Shackelford SD, et al. (2006). Effects of calpastatin and micro-calpain markers in beef cattle on tenderness traits. J. Anim. Sci. 84: 520-525. http://dx.doi.org/10.2527/2006.843520x

Chung H and Davis M (2012). Effects of genetic variants for the calpastatin gene on calpastatin activity and meat tenderness in Hanwoo (Korean cattle). Meat Sci. 90: 711-714. http://dx.doi.org/10.1016/j.meatsci.2011.10.017

Corva P, Soria L, Schor A, Villarreal E, et al. (2007). Association of CAPN1 and CAST gene polymorphisms with meat tenderness in Bos Taurus beef cattle from Argentina. Genet. Mol. Biol. 30: 1064-1069. http://dx.doi.org/10.1590/ $\underline{\text { S1415-47572007000600006 }}$

Crouse JD, Cundiff LV, Koch RM, Koohmaraie M, et al. (1989). Comparisons of Bos indicus and Bos Taurus inheritance for carcass beef characteristics and meat palatability. J. Anim. Sci. 67: 2661-2668. http://dx.doi.org/10.2527/ jas1989.67102661x

Curi RA, Chardulo LAL, Mason MC, Arrigoni MDB, et al. (2009). Effect of single nucleotide polymorphisms of CAPN1 and CAST genes on meat traits in Nellore beef cattle (Bos indicus) and in their crosses with Bos taurus. Anim. Genet. 40: 456-462. http://dx.doi.org/10.1111/j.1365-2052.2009.01859.x

Dransfield E, Etherington DJ and Taylor MAJ (1992). Modelling post-mortem tenderisation-II: Enzyme changes during storage of electrically stimulated and non-stimulated beef. Meat Sci. 31: 75-84. http://dx.doi.org/10.1016/03091740(92)90073-D

Dransfield E (1993). Modelling post-mortem tenderisation-IV: Role of calpains and calpastatin in conditioning. Meat Sci. 34: 217-234. http://dx.doi.org/10.1016/0309-1740(93)90029-H

Falconer DS and Mackay TFC (2001). Introduccion a la genética cuantitativa. 4th edn. Zaragoza, 469.

Gallinger MM, Marcelia M, Garcia PT, Lasta J, et al. (1992). Meat quality of zebu crossbred: sensory and mechanical evaluation. In: 38th ICoMST, Clermont-Ferrand, France. Proceedings Clermont-Ferrand, 45-48.

Geesink GH, Kuchay S, Chishti AH and Koohmaraie M (2006). Micro-calpain is essential for postmortem proteolysis of muscle proteins. J. Anim. Sci. 84: 2834-2840. http://dx.doi.org/10.2527/jas.2006-122

Hadlich JC, Morales DC, Silveira AC, Oliveira HN, et al. (2006). Efeito do colágeno na maciez da carne de bovinos de distintos grupos genéticos. Acta Sci. Anim. Sci 28: 57-62. http://dx.doi.org/10.4025/actascianimsci.v28i1.664

Johnston DJ and Graser HU (2010). Estimated gene frequencies of GeneSTAR markers and their size of effects on meat tenderness, marbling, and feed efficiency in temperate and tropical beef cattle breeds across a range of production systems. J. Anim. Sci. 88: 1917-1935. http://dx.doi.org/10.2527/jas.2009-2305

Kastner CL and Henrickson RL (1969). Providing uniform meat cores for mechanical Shear Force measurement. J. Food Sci. 34: 603-605. http://dx.doi.org/10.1111/j.1365-2621.1969.tb12100.x

Koohmaraie M (1988). The role of endogenous proteases in meat tenderness. In: Reciprocal Meat Conference, 1988, Laramie, Proceeding. 89-100.

Koohmaraie M (1996). Biochemical factors regulations the toughening and tenderization process of meat. J. Anim. Sci. 43: 193-201.

Koohmaraie M, Kent MP, Shackelford SD, Veiseth E, et al. (2002). Meat tenderness and muscle growth: is there any relationship? Meat Sci. 62: 345-352. http://dx.doi.org/10.1016/S0309-1740(02)00127-4

Lee SH, Kim SC, Chai HH, Cho SH, et al. (2014). Mutations in calpastatin and $\mu$-calpain are associated with meat tenderness, flavor and juiciness in Hanwoo (Korean cattle): molecular modeling of the effects of substitutions in the calpastatin/ $\mu$-calpain complex. Meat Sci. 96: 1501-1508. http://dx.doi.org/10.1016/j.meatsci.2013.11.026

Li X, Ekerljung M, Lundström K and Lundén A (2013). Association of polymorphisms at DGAT1, leptin, SCD1, CAPN1 and CAST genes with color, marbling and water holding capacity in meat from beef cattle populations in Sweden. Meat Sci. 94: 153-158. http://dx.doi.org/10.1016/j.meatsci.2013.01.010

Mellgren RL, Lane RD and Mericle MT (1989). The binding of large calpastatin to biologic membranes is mediated in part by interaction of an amino terminal region with acidic phospholipids. Biochim. Biophys. Acta 999: 71-77. http:// dx.doi.org/10.1016/0167-4838(89)90032-0

Morgan JB, Wheeler TL, Koohmaraie M, Savell JW, et al. (1993). Meat tenderness and the calpain proteolytic system in longissimus muscle of young bulls and steers. J. Anim. Sci. 71: 1471-1476.

Olerup O and Zetterquist H (1992). HLA-DR typing by PCR amplification with sequence-specific primers (PCR-SSP) in 2 hours: an alternative to serological DR typing in clinical practice including donor-recipient matching in cadaveric transplantation. Tissue Antigens 39: 225-235. http://dx.doi.org/10.1111/j.1399-0039.1992.tb01940.x

Page BT, Casas E, Quaas RL, Thallman RM, et al. (2004). Association of markers in the bovine CAPN1 gene with meat

Genetics and Molecular Research 16 (1): gmr16018957 
tenderness in large crossbred populations that sample influential industry sires. J. Anim. Sci. 82: 3474-3481. http:// dx.doi.org/10.2527/2004.82123474x

Pinto LFB, Ferraz JBS, Meirelles FV, Eler JP, et al. (2010). Association of SNPs on CAPN1 and CAST genes with tenderness in Nellore cattle. Genet. Mol. Res. 9: 1431-1442. http://dx.doi.org/10.4238/vol9-3gmr881

Pinto LF, Ferraz JB, Pedrosa VB, Eler JP, et al. (2011). Single nucleotide polymorphisms in CAPN and leptin genes associated with meat color and tenderness in Nellore cattle. Genet. Mol. Res. 10: 2057-2064. http://dx.doi. org/10.4238/vol10-3gmr1263

Ramsey CB, Cole JW, Bernadine HM and Temple RS (1963). Effects of type and breed of British, zebu and dairy cattle on production, palatability and composition. II. Palatability differences and cooking losses as determined by laboratory and family panels. J. Anim. Sci. 22: 1001-1008. http://dx.doi.org/10.2527/jas1963.2241001x

SAS Institute (2003). Statistical analysis system: User's guide, Version 9.1. (Software) Cary. USA.

Schenkel FS, Miller SP, Jiang Z, Mandell IB, et al. (2006). Association of a single nucleotide polymorphism in the calpastatin gene with carcass and meat quality traits of beef cattle. J. Anim. Sci. 84: 291-299. http://dx.doi. org/10.2527/2006.842291x

Shackelford SD, Koohmaraie M, Miller MF, Crouse JD, et al. (1991). An evaluation of tenderness of the longissimus muscle of Angus by Hereford versus Brahman crossbred heifers. J. Anim. Sci. 69: 171-177. http://dx.doi. org/10.2527/1991.691171x

Smith TP, Casas E, Rexroad CE, 3rd, Kappes SM, et al. (2000). Bovine CAPN1 maps to a region of BTA29 containing a quantitative trait locus for meat tenderness. J. Anim. Sci. 78: 2589-2594. http://dx.doi.org/10.2527/2000.78102589x

de Souza MM, Niciura SCM, Tizioto PC, Ibelli AMG, et al. (2016). Allele- and parent-of-origin-specific effects on expression of the KCNJ11 gene: A candidate for meat tenderness in cattle. Genet. Mol. Res. 15: http://dx.doi. org/10.4238/gmr. 15038549 .

White SN, Casas E, Wheeler TL, Shackelford SD, et al. (2005). A new single nucleotide polymorphism in CAPN1 extends the current tenderness marker test to include cattle of Bos indicus, Bos taurus, and crossbred descent. J. Anim. Sci. 83: 2001-2008. http://dx.doi.org/10.2527/2005.8392001x

\section{Supplementary material}

Figure S1. Least square means for shear force in 7 (SF7D), 14 (SF14D) and 21 (SF21D) days of maturation of individuals in each genotype to the marker CAPN530, CAPN4751, CAPN4753 and UOGCAST1.

Genetics and Molecular Research 16 (1): gmr16018957 